\title{
Use of a transparent cap for endoscopic drainage of a pancreatic pseudocyst
}

The usefulness of a transparent endoscope cap in difficult cases has been described [1]. The use of this device to facilitate endoscopic access to a pancreatic pseudocyst prior to drainage has not been reported before.

We report the case of a 47-year-old man with abdominal pain 3 months after acute biliary pancreatitis. CT scan showed a $12-\mathrm{cm}$ pseudocyst in the pancreatic body and in close contact $(<1 \mathrm{~cm})$ with the posterior gastric wall with no collateral veins. Endoscopic ultrasound (EUS) showed typical pseudocyst findings and the optimal puncturing site was marked with a forceps. Using a therapeutic duodenoscope, a small incision (triple-lumen needle knife) was made, but severe bleeding occurred ( $\bullet$ Fig. 1). Adrenaline $1: 10000(5 \mathrm{ml})$ was injected without success. We changed to a therapeutic gastroscope equipped with a transparent cap. This gave a better view of the active bleeding, and after application of two hemoclips the bleeding stopped ( $\bullet$ Fig. 2). Noticing the appropriate and stable position obtained with the transparent cap against the posterior gastric wall, we decided to continue. Two centimeters from the hemoclips another small incision was made with a triple-lumen needle knife, and using this catheter the gastric wall was punctured ( $\bullet$ Fig. 3), leading the guide wire into the pseudocyst ( $\bullet$ Fig. 4). Frequently, the best gastric compression site is in a difficult position for endoscopic drainage, and a freehand incision or puncturing technique may misdirect placement of the guide wire. However, we found that using the transparent cap a stable endoscopic position can be obtained and cutting and/or puncturing can be carried out with more confidence. After leading the guide wire into the cyst we changed to a duodenoscope; tract dilatation was carried out and two 10-Fr double pigtail stents were inserted. We consider that the transparent cap can be a very useful accessory to maintain the position of the endoscope in cases of difficult pancreatic pseudocyst access.

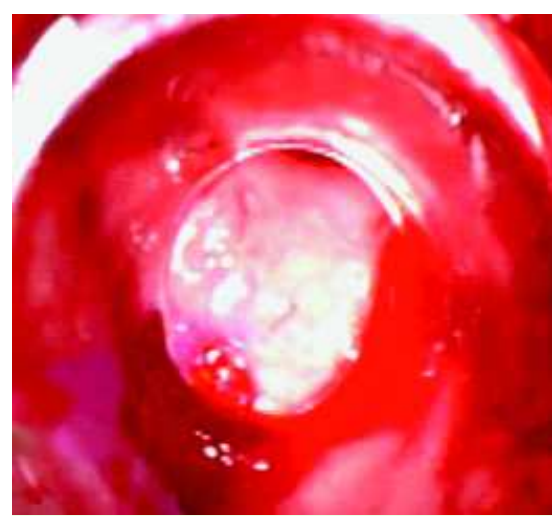

Fig. 1 Active bleeding after needle knife incision.

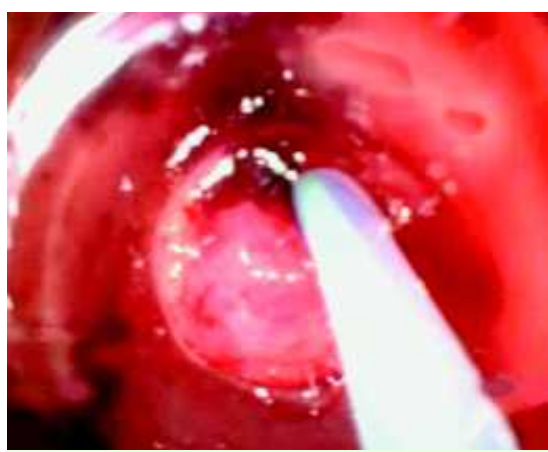

Fig. 3 Cutting and puncturing the posterior gastric wall with a triple-lumen needle knife.

\section{J. A. Gonzalez-Gonzalez, E. Mendoza- Fuerte, A. A. Garza-Galindo,}

J. A. Leal-Salazar, H. Maldonado-Garza Facultad de Medicina y Centro Regional para el Estudio de Enfermedades Digestivas, Hospital Universitario Dr. José Eleuterio González, Universitad Autonoma de Nuevo Leon, Monterrey, Nuevo Leon, México

\section{References}

$1 \mathrm{Kim}$ JI, Kim SS, Park S et al. Endoscopic hemoclipping using a transparent cap in technically difficult cases. Endoscopy 2003; 35: 659-662

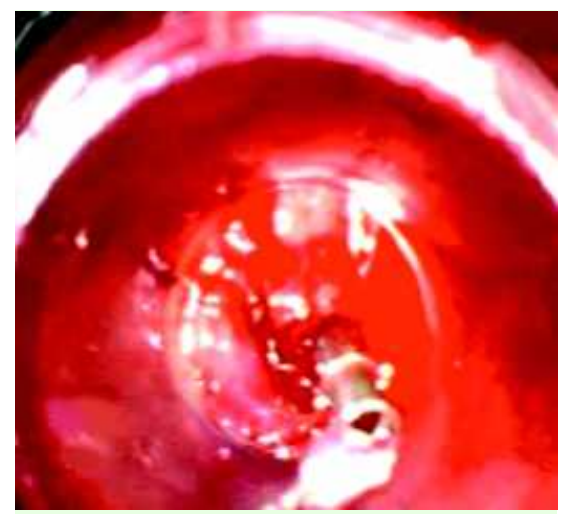

Fig. 2 Successful treatment of bleeding with hemoclip.

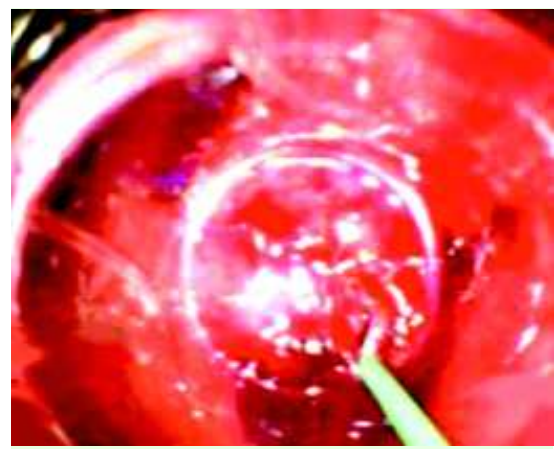

Fig. 4 Transparent cap and guide wire in the pseudocyst.

Bibliography

DOI $10.1055 / \mathrm{s}-2008-1077439$

Endoscopy 2008; 40: E206

(c) Georg Thieme Verlag KG Stuttgart · New York . ISSN 0013-726X

\section{Corresponding author}

\section{J. A. Gonzalez-Gonzalez, MD}

Hospital Universitario José Eleuterio González Centro Regional para el Estudio de Enfermedades Digestivas

Av. Madero y Gonzalitos SN

Monterrey

Nuevo Leon 64460

Mexico

Fax: +52-81-83486068

joseagonz@yahoo.com 